\title{
Social positioning in small group interactions in an investigative science learning environment physics class
}

\author{
David T. Brookes $\odot$ \\ Department of Physics, California State University, \\ Chico, 400 W. 1st Street, Chico, California 95929-0202, USA \\ Yuehai Yang \\ Department of Natural Sciences, Oregon Institute of Technology, \\ 3201 Campus Drive, Klamath Falls, Oregon 97601, USA \\ Binod Nainabasti \\ Department of Physics, Lamar University, 4400 MLK Parkway, Beaumont, Texas 77705, USA
}

(Received 17 August 2020; accepted 8 January 2021; published 25 January 2021)

\begin{abstract}
We conducted a semester-long ethnographic study of group work in a physics class that implemented the investigative science learning environment approach. Students' conversations were videotaped while they were engaged in group learning activities. Our primary research goal was to better understand what factors made some groups more effective than others. We developed a coding scheme that uses particular modality markers such as hedging and upward inflection to identify how students position themselves in these group conversations. Additionally we quantified group effectiveness by how many key ideas in a particular activity a group negotiated and resolved through the course of their conversation. This research builds on theories of social positioning that posit that groups are more effective when their discussion is more equitable. Our exploratory study indicates that groups whose participants position themselves in a more equitable way, are more effective at completing challenging physics activities and resolving areas of confusion that arise.
\end{abstract}

DOI: 10.1103/PhysRevPhysEducRes.17.010103

\section{INTRODUCTION}

This research began out of a set of informal observations of a highly student-centered interactive classroom. The classroom consisted of groups of students working together on investigative science learning environment (ISLE) activities [1] in a studiolike setting [2] with little formal lecturing.

Central to the ISLE approach is the idea that physics students acquire scientific habits of mind (often referred to as scientific abilities) and a deeper understanding of where scientific knowledge comes from by engaging in a process of doing physics that mirrors the practices and reasoning that physicists implement as they construct their knowledge [3]. Students who learn physics in a class that implements the ISLE approach engage in carefully scaffolded but openended activities that have specific epistemic (knowledgegenerating) goals. Students are not told what to do or how

Published by the American Physical Society under the terms of the Creative Commons Attribution 4.0 International license. Further distribution of this work must maintain attribution to the author(s) and the published article's title, journal citation, and DOI. to do it, but rather are asked to advance their knowledge of a particular physical system under investigation by designing experiments, analyzing scenarios using multiple representational tools, or applying their knowledge to achieve some meaningful real-world goal (e.g., "design and implement two independent ways to measure the coefficient of friction between your shoe and a floor tile"). Prior research has shown that the ISLE approach is effective in its primary goal of helping students develop scientific reasoning abilities in the context of physics as compared to students who learn physics through a more traditional approach [4]. ISLE students are more aware of how they know what they know as compared to traditionally taught students [3]. Finally, ISLE students have shown significant positive shifts in their attitudes towards physics [5].

Just as physicists collaborate to advance their knowledge, a thriving classroom scientific learning community [6] is key to the ISLE approach. In the class that was the subject of our research, students worked in their groups using $2^{\prime} \times 2.5^{\prime}$ whiteboards, and tried to reach communal consensus about their ideas with whole-class "board" meetings $[7,8]$. We became interested in how this learning community was functioning. What we observed was that each year there were a few groups of students who stood 
apart from the others. These groups were pivotal groups in the whole class board meetings where students were expected to converge on consensus ideas. Their ideas were deeper, more insightful and frequently defined the direction in which the class moved. Two questions that arose were what made these effective groups function better and what were the students in those groups doing differently from their peers?

We decided to video randomly selected episodes of learning activities where students worked together in their groups. We gathered and analyzed data throughout the semester. We took a grounded theory approach [9] to analyzing our data, coming up with descriptive codes while simultaneously reading the literature on group collaboration. This literature is summarized in Sec. II. We started by looking for patterns in student participation when they talked to each other. In our initial approach we simply tried to code students' conversation for being "on topic" if they were talking about physics, "off topic/disengaged" if they were doing something obviously unrelated to the topic at hand, "writing on the whiteboard" or "uncodable" if they were silent. We found that off-topic behavior was predictive of individual student success in the course [10] as measured by their exam scores. On-topic behavior was also significantly correlated with exam scores, but the correlation was weak $[10,11]$. In addition, while members of some groups clearly interacted with each other much more than in other groups, thereby creating more opportunities for discussion and sense making, there were several groups whose members interacted on topic a lot and yet failed to engage in deep sense making or make significant progress on the activities. We needed to look deeper. We started looking at how students were talking to each other in their intragroup conversations and we started to identify regular patterns in their language. In this paper, we will present and test a specific hypothesis that we developed through our own observations and through reading the literature: The hypothesis is that groups are more effective when group members open the collaborative space to discussion and sense making by making statements that are prefaced by hedges or other similar means that suggest a degree of uncertainty in the ideas that are being presented. The data we have analyzed support this hypothesis and we will discuss (with examples) why those particular behaviors might be pivotal for the functioning of effective groups.

\section{PARTICIPATION AND GROUP WORK}

\section{A. The participationist framework}

The transmissionist or acquisitionist views of learning both view knowledge in the ontological category of an object that can be given to or acquired by students [12]. In contrast, the investigative science learning environment approach, around which our classroom is structured, is firmly rooted in the participationist theory of learning [1].
This view treats knowledge as an ontological process and posits that students learn by engaging or participating in that knowledge-building process, turning the classroom into a knowledge-building community [13]. The origins of the participationist theoretical framework lie in the understanding that students can be viewed as participants in a learning community and wherein they transform their participation from peripheral to central [14], or in terms of growing into and transforming the sociocultural activities of that community [15]. Importantly, it is the kind of participation that determines what is learned [15]. In a classroom following the ISLE approach, students participate in the sociocultural practices of physics. These practices include both epistemic practices [5] and representational [16] or semiotic [17] practices. By engaging in these practices they are learning physics by doing physics. In summary, if knowledge is a process of knowing, the way in which students participate in that process becomes paramount. This is the theoretical perspective that forms the basis of the research we will present in this paper.

As mentioned in the introduction, within the broader framework of participation, we became interested in how students participated in group activities and whether this could account for why some groups appear to be more successful than others.

\section{B. Groups and group effectiveness}

Why are groups and group work important to studentcentered inquiry learning environments? The ISLE approach is typically used to structure a highly studentcentered inquiry class where students are expected to learn physics by thinking like physicists [18]. They engage in epistemologically authentic inquiry tasks [19] that can be extremely challenging. The activities that students engage in frequently ask them to design experiments to achieve certain epistemic goals and are highly task interdependent where task interdependence is defined as the degree to which group members need to collaborate, coordinate, or interact in order to complete the assigned task [20]. In short, the task of having students create physics knowledge on their own is difficult and working in groups can facilitate this creative process.

Groups can function as a source of knowledge construction [21]. It is understood that group members bring diverse views and experiences to the task. Through verbal discussion and mediating their discussion with a variety of semiotic resources [17], groups converge on shared meaning [22] and consensus understanding [7]. Additionally, research has shown that students learn more from collaborating with each other as opposed to working alone and the quality of the group's interpersonal interactions directly affects learning and transfer [23,24].

In trying to understand why groups are successful and effective or not, the literature divides the factors that contribute to group effectiveness into two categories: 
structural factors and interpersonal factors. Structural factors are factors like the nature of the task that the group is being asked to complete. For example, Mesch, Johnson, and Johnson [25] showed that both positive task and reward interdependence are mechanisms that drive group performance. Much early research on groups has treated the group as a black box, manipulating structural factors and assessing how those affect group performance [26]. More recent research has started to look inside the black box at interpersonal factors that affect group effectiveness. Research has begun to focus more on how the group members interact and relate to each other as they work.

Various interpersonal factors that affect groups have been identified. Williams Woolley and colleagues [27], in measuring the collective intelligence of a group (using a number of open-ended group tasks), found that the social sensitivity of the group members was more predictive of the collective intelligence of the group than individual IQs of the group members. Similarly, Barron found that there was no correlation between prior math performance and the success of groups of three sixth graders engaged in a challenging math problem [23].

Edmondson [28] found that team learning behavior was highly dependent on the climate of psychological safety in the team. Julia Rozovsky, a researcher at Google, found that the effectiveness of a team is primarily determined by how the people on the team interact: "Who is on a team matters less than how the team members interact, structure their work, and view their contributions." [29] She too has identified "psychological safety" as the key variable that predicts whether a team will be successful or not. Psychological safety is defined by Edmondson as “... a shared belief that the team is safe for interpersonal risk taking," giving members the confidence to speak up; and, "This confidence stems from mutual respect and trust among team members." [28] (p. 354)

While prior research has been based on the subjective perceptions of group members [21], we want to go beyond this in our research. In this paper, we aim to shed light on the underlying processes that promote psychological safety in a group and the feeling of mutual respect and appreciation in an ecologically valid classroom setting.

\section{Group interactions viewed through a participationist lens}

The idea of positioning is a relatively new construct in the participationist framework. Esmonde [30] has suggested that students position themselves in interactions and that this act of positioning can create or reduce learning opportunities for others in the group. Bonderup Dohn [31] has argued that students can dynamically position themselves moment by moment, thereby negotiating a transient participatory identity for themselves within a particular activity that they are engaged in: "The 'expert' students did not explicitly say 'I am an expert,' but they took the lead in group discussions with the self-assurance of the expert." (p. 200) While students can position themselves as experts, Conlin and Scherr have shown that students can create epistemic distance (thereby opening the space to sense making) through humor and by rephrasing a statement as a question [32]. How participants position themselves can be viewed as a matter of equity: For Esmonde, equity in a group is the fair distribution of opportunities to learn. This includes both access to the content and to the discourse practices of the field, but also access to positional identities [30].

Researching group interactions, Fragale [33] demonstrated that when groups of people are asked to collaborate to solve a problem, the way they talk to each other is critical to whether ideas are heard and taken up by the group. Group members who made hedged statements or softened their statement with an attached question, achieved higher status and recognition when the task was more interdependent whereas the powerful speakers (members who made emphatic or unhedged statements) were accorded higher status when the activity had lower task interdependence. An emphatic or unhedged statement is one like "The answer is X," while a hedged version of the same statement would be "I think the answer might be X." In the field of linguistics, it is understood that when language users use language to communicate information, they introduce uncertainty into an otherwise emphatic statement of fact, by using hedges and even upward inflection at the end of the sentence, denoting an "epistemic stance" towards the information contained therein [34]. This is referred to as "modalizing" the statement [35].

In developing our coding scheme described in Sec. III C below we have combined these disparate ideas that (a) people position themselves as experts or novices in a given conversation, and (b) people introduce degrees of uncertainty into their statements through hedges and inflections, thereby softening their "expert" position. In this way we have extended previous work on positioning in which researchers mainly focused on students assuming either an expert or a novice position in conversation.

\section{Measuring group learning effectiveness}

Measuring group effectiveness is one of the most difficult theoretical issues that we faced in our research. There is a paucity of literature that adequately discusses how to directly measure how effective a group is. Williams Woolley and colleagues [27] measured collective intelligence of a group through a series of open-ended tasks like "think up as many unique uses for a brick as you can in 1 minute." Both Barron [23], and Menekse and Chi [24] used a post-test to measure student learning from prior group collaboration, but these approaches sacrifice the ecological validity of an actual classroom setting for a more controlled lab intervention. Measuring how effective a group is in an ecologically valid classroom learning 
context is less well defined. For example, one may think to measure group effectiveness by how quickly and accurately the group completes an assigned learning activity. Yet, how many key points of each learning activity did the group examine and really grapple with? A group may complete a task quickly, but not really engage in the difficult parts of the task. On the other hand, a group can get stuck and go nowhere, following irrelevant tangents and becoming lost, resulting in an incomplete assignment.

Edmondson [28] provides a definition of team learning behavior that is helpful to understand group learning effectiveness:

"I conceptualize learning at the group level of analysis as an ongoing process of reflection and action, characterized by asking questions, seeking feedback, experimenting, reflecting on results, and discussing errors or unexpected outcomes of actions. For a team to discover gaps in its plans and make changes accordingly, team members must test assumptions and discuss differences of opinion openly rather than privately or outside the group. I refer to this set of activities as learning behavior, as it is through them that learning is enacted at the group level." (p. 353)

This description served as an inspiration for our approach to quantifying group learning effectiveness (or "group effectiveness" for short) described in Sec. III D below. An effective group does more than get correct answers, they engage in contentious issues and also find ways to resolve their uncertainties and difficulties, using the instructor or textbook as a resource; or (more preferably) by engaging in the practices of physics (including experimentation, examining assumptions, and/or coordinating semiotic resources, etc.), reaching consensus on their own.

\section{METHODOLOGY}

\section{A. A description of the classroom}

Our research took place in a student-centered introductory university-level calculus-based physics class of 30 students. Students were ethnically diverse and many were first-generation college students. Students engaged in a variety of epistemically authentic guided inquiry learning activities [36] based on the ISLE approach [3]. Working in 10 groups of 3 students each, students would sometimes engage in experimentation, sometimes working on developing a model, or applying physical ideas to solve a realworld problem using a group whiteboard. Groups then presented their ideas to each in a whole-class board meeting, reaching consensus through discussion and guidance from the instructor. The instructor would then sometimes summarize a key point or idea in a short 5-min lecture. Activities were open ended, sometimes ill structured, often at the edge of the zone of proximal development of the students [37], and generally could not be completed by even the very best students working alone. Additionally, task and reward interdependence were built into the environment with shared grades for lab activities. Board meetings, where groups were asked to present their results, inculcated a sense of shared enterprise in the learning process.

Students were audio-video recorded 14 separate times during the semester. The room was arranged in such a way that there were 5 rectangular tables with two groups of 3 seated opposite each other at the same table. This design choice followed the recommendation of the SCALE-UP project [38], that the learning environment should be designed to allow local interactions between groups, thereby fostering smaller communities within the larger classroom learning community. Each table was recorded using a miniature camera mounted in the ceiling. A voice recorder was placed in the middle of the table to acquire the best possible audio. The audio and video tracks were synced up afterwards in Final Cut Pro. In total, we gathered about $70 \mathrm{~h}$ of data. A view of one table setup is shown in Fig. 1.

Students were randomly assigned to their groups at the start of the semester. They were then randomly reassigned to new groups by the instructor one week later to allow them to meet new people and experience a new group dynamic. One week after that, students were instructed to choose their own groups (without the intervention of the instructor) and those groups remained together for the rest of the semester. This is important because the episodes of student work we chose to analyze are all from the months of October and November, after the groups were well established. We decided not to analyze episodes recorded in September because groups were still getting themselves established and learning how to work together effectively. We labeled the ten groups A-J.

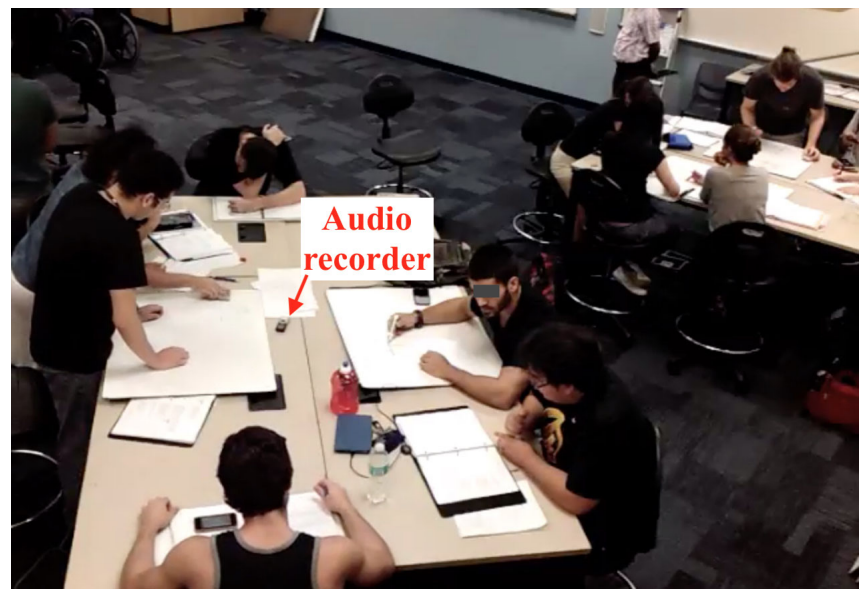

FIG. 1. A view of the setup of one table, as viewed from the video camera. 


\begin{tabular}{|c|c|c|c|}
\hline \multicolumn{2}{|c|}{ Episode 1: "Scale-tilt" activity } & \multicolumn{2}{|c|}{ Date: October 3} \\
\hline \multicolumn{4}{|c|}{$\begin{array}{l}\text { Observe and represent } \\
\text { Place an object on a scale, note the reading, then tilt the scale } 10^{\circ} \text { or so. Make sure the } \\
\text { object does not slide. Note what happens to the reading on the scale and then draw a force } \\
\text { diagram for each situation }\end{array}$} \\
\hline Episode 2: "Roller coas & er" activity & \multicolumn{2}{|c|}{ Date: October 15} \\
\hline \multicolumn{4}{|c|}{$\begin{array}{l}\text { Represent a process in multiple ways } \\
\text { For the rollercoaster car, fill in the table that follows: }\end{array}$} \\
\hline $\begin{array}{l}\text { Rollercoaster situation, circle } \\
\text { the system }\end{array}$ & $\begin{array}{l}\text { Indicate the } \\
\text { direction of } \vec{a} \text {. }\end{array}$ & $\begin{array}{l}\text { Draw a force } \\
\text { diagram for the car. }\end{array}$ & $\begin{array}{l}\text { Apply } \\
a_{r}=\frac{v^{2}}{r}=\frac{\sum F_{\text {in radial dir. }}}{m}\end{array}$ \\
\hline \multicolumn{4}{|l|}{$\begin{array}{l}\text { (a) The car glides at constant } \\
\text { speed along a } \\
\text { frictionless } \\
\text { level track }\end{array}$} \\
\hline \multicolumn{4}{|l|}{$\begin{array}{l}\text { (b) The car moves through a } \\
\text { frictionless } \\
\text { circular dip in } \\
\text { the track. }\end{array}$} \\
\hline \multicolumn{4}{|l|}{$\begin{array}{l}\text { (c) The car } \\
\text { moves, } \\
\text { inverted, past } \\
\text { the top of a } \\
\text { frictionless loop-the-loop. }\end{array}$} \\
\hline \multicolumn{2}{|c|}{ Episode 3: "Energy bar chart" activity } & \multicolumn{2}{|c|}{ Date: November 12} \\
\hline \multicolumn{4}{|c|}{$\begin{array}{l}\text { Real-world application } \\
\text { A 5-kg box is sliding across a rough surface sliding with an initial velocity of } 10 \mathrm{~m} / \mathrm{s} \text {. } \\
\text { There is a coefficient of kinetic friction between the box and the surface of } 0.6 \text {. How far } \\
\text { does the box slide? Note: practice using an energy approach rather than Newton's laws } \\
\text { and kinematics to figure this out. }\end{array}$} \\
\hline
\end{tabular}

FIG. 2. The questions that students were working on for the three episodes we analyzed.

\section{B. Coded episodes}

We selected three episodes of student work to code. The questions that students were asked to work on for each of the episodes are shown in Fig. 2. The episodes were selected because they were typical of all the episodes in the October-November time period.

\section{Coding scheme}

The coding scheme we developed identifies five "positional moves" that students can make during conversation. A student who positions themselves as an expert providing an idea or answering a question can do so in a "firm" manner or "softened" (modalized) manner, using hedges, upward inflection and other means of indicating uncertainty. A student who assumes a "novice" position by asking a question, can do this in different ways: They can ask a probing question that potentially contributes to driving the conversation forward, or can ask a question or make a statement that suggests some degree of helplessness or lack of knowledge. Lastly, a student can make comments that have little conceptual content, yet support the discussion in a productive manner by directing the focus of the group, discussing the purpose of an activity, or providing encouragement or support to one or more other group members. We call these "facilitation" moves. Table I describes and gives examples of each positional move.

Additionally, we applied the following rules when coding 15 second segments of conversation: If a student only made firm statements in the interval they were coded 1. If, in addition to firm statements they also made any hedge in that $15 \mathrm{sec}$ interval, they were coded 2 instead. If a student made firm statements and asked a question in an interval they were coded 2 . If a student only asked questions in an interval they were coded 3 or 4 by the criteria in the table. If a student only made a facilitation move or moves in the $15 \mathrm{sec}$ interval they were coded 5, otherwise the facilitation was ignored. Off-topic conversations were not coded, thus coded segments represent time spent engaged in on-topic discussion. Finally, affirmative statements like "yes," "I agree," and "right!" were not considered in the coding scheme since we found it impossible to assign an unambiguous positional identity to these.

\section{Coding and interrater reliability}

For each group in each episode, we selected a 10-15 min continuous segment to code. We coded each group separately. We only coded conversations between the three

TABLE I. Table of 5 positional moves including examples.

\begin{tabular}{|c|c|c|}
\hline $\begin{array}{l}\text { Positional } \\
\text { move (code) }\end{array}$ & Description & Example(s) \\
\hline Expert (1) & $\begin{array}{l}\text { Firm statements of fact or firm or strong } \\
\text { disagreement. }\end{array}$ & $\begin{array}{l}\text { Thomas (Ep. 3) "No gravitational energy, so work is equal to mv } \\
\text { initial, squared, minus mv final squared." [downward inflection] }\end{array}$ \\
\hline $\begin{array}{r}\text { Intermediate } \\
\text { expert (2) }\end{array}$ & $\begin{array}{l}\text { Softened statements or softened disagreement, } \\
\text { using hedges or upward inflection at the end } \\
\text { of a sentence. }\end{array}$ & $\begin{array}{l}\text { José (Ep. 1): "And it's the same as this one, right?" } \\
\text { Helen (Ep. 2): "So, direction of acceleration should be...up" [there } \\
\text { is a slight pause before "up" and it is inflected upwards.] }\end{array}$ \\
\hline $\begin{array}{l}\text { Intermediate } \\
\text { novice }(3)\end{array}$ & Questions that drive the conversation. & $\begin{array}{l}\text { Chris (Ep 2.) "Can we say that constant speed is the same as } \\
\text { constant velocity?" } \\
\text { Jessica (Ep. 3): "What about the change in energy initial?" }\end{array}$ \\
\hline Novice (4) & $\begin{array}{l}\text { Questions or statements that convey } \\
\text { helplessness or general confusion. }\end{array}$ & Joseph (Ep 1): "I don't know what the tilt would be." \\
\hline Facilitator (5) & $\begin{array}{l}\text { Metalevel statements or questions that facilitate } \\
\text { the discussion in some way. }\end{array}$ & $\begin{array}{l}\text { Paul (Ep. 2): "Just like we got here. Alright!" } \\
\text { [Paul high fives Helen next to him.] } \\
\text { Donald (Ep. 3): "It says place an object on the scale, } \\
\text { note the reading." }\end{array}$ \\
\hline
\end{tabular}


TABLE II. Group effectiveness scores for all 10 groups for the roller coaster activity.

\begin{tabular}{|c|c|c|c|c|c|c|c|c|c|c|}
\hline Group & A & $\mathrm{B}$ & $\mathrm{C}$ & $\mathrm{D}$ & $\mathrm{E}$ & $\mathrm{F}$ & $\mathrm{G}$ & $\mathrm{H}$ & I & $\mathrm{J}$ \\
\hline (b) Identify 2 forces ( $F_{\text {track on car }}$ and $m g$ only) & 1 & 1 & 0 & 1 & 1 & 1 & 0 & 3 & 3 & 1 \\
\hline (b) Get direction of $a_{\mathrm{r}}$ (up) & 2 & 3 & 2 & 3 & 2 & 3 & 0 & 1 & 1 & 0 \\
\hline (b) Recognize $F_{\text {track on car }}>m g$-connected to direction of $a_{\mathrm{r}}$ & 3 & 0 & 0 & 1 & 1 & 2 & 0 & 1 & 1 & 0 \\
\hline (c) Get direction of $a_{\mathrm{r}}$ (down) & 2 & 0 & 1 & 1 & 0 & 3 & 0 & 0 & 1 & 0 \\
\hline (c) Identify 2 forces ( $F_{\text {track on car }}$ and $m g$ only) & 1 & 1 & 0 & 0 & 0 & 1 & 0 & 1 & 0 & 0 \\
\hline (c) Recognize $F_{\text {track on car }}$ points downwards & 3 & 0 & 0 & 0 & 0 & 2 & 0 & 2 & 0 & 0 \\
\hline (c) Connect $F_{\text {track on car }}+m g$, to $a_{\mathrm{r}}$ & 2 & 0 & 1 & 0 & 0 & 2 & 0 & 1 & 0 & 0 \\
\hline Total score & 14 & 5 & 4 & 6 & 4 & 14 & 0 & 9 & 6 & 1 \\
\hline
\end{tabular}

group members; any conversation between the two groups seated at the same table was ignored. We broke the transcript into $15 \mathrm{sec}$ segments and assigned a position to each group member according to the coding scheme described above. We examined interrater reliability by having two coders independently code the same transcript. Most discrepancies between coders occurred because the boundaries of the 15-second time intervals had to be treated somewhat elastically because sometimes the boundary occurred while a student was in the middle of a sentence. After resolving boundary discrepancies we were able to achieve an average Cohen's Kappa of 0.79 across 5 randomly selected groups. Having established reliability, the remaining groups were coded by one coder.

\section{Quantifying group effectiveness}

We also need a way to quantify the learning effectiveness of each group. We created a quantitative measure of group effectiveness as follows: Each activity had a number of key points that students need to discuss or wrestle with in order to figure out the problem and come out with an answer. We identified all the key points that each activity entailed. Then the group was scored on each key point out of 3 points total: 1 point if the group members correctly addressed a key point without discussion or questioning it, and without justification, 1 point for verbally justifying their reasoning using normative physics knowledge, and 1 point if the group questioned and wrestled with a particular key point. We identified key points as common stumbling blocks such as in part (b). of the roller coaster activity, where the car is at the bottom of the loop, students tend to start from the idea that $F_{\text {track on car }}=F_{\text {Earth on car }}$ from part (a), but they need to recognize that $F_{\text {track on car }}>F_{\text {Earth on car }}$ in order to keep the car moving in circular motion at that point. The scoring of the roller coaster activity is shown in Table II.

\section{FINDINGS AND ANALYSIS}

\section{A. Quantitative analysis}

\section{Positional coding and group effectiveness}

Figures 3-5 show group positional distribution during the three episodes, i.e., percentage of code $1,2,3$, 4, and 5 as a fraction of total number of social positioning codes for each group. Note that percentages do not add to $100 \%$ because groups could either be engaged in off-topic conversation or completely silent for certain 15 -sec intervals of the segment we coded.

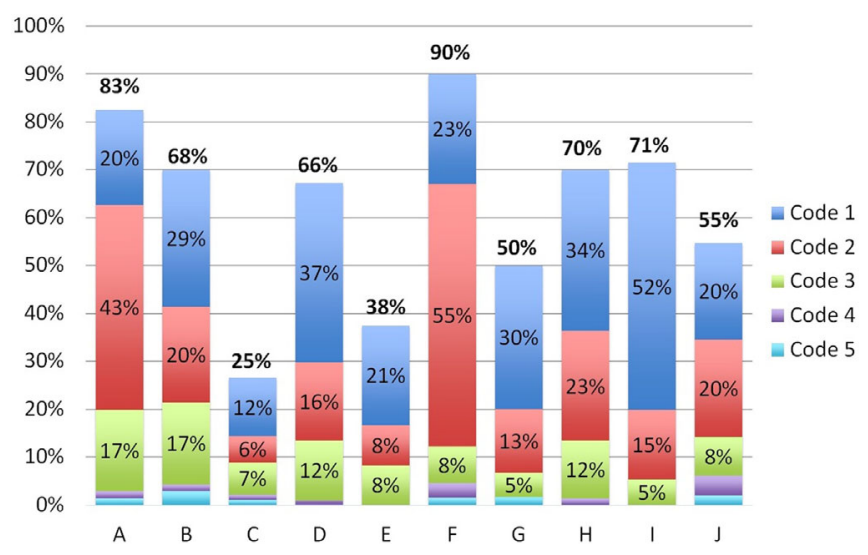

FIG. 3. The distribution of social positions for each group in "scale tilt" activity, episode 1 . Columns represent percentage of $1,2,3,4$, and 5 codes as a fraction of total number of codes, scaled by the amount of coded time.

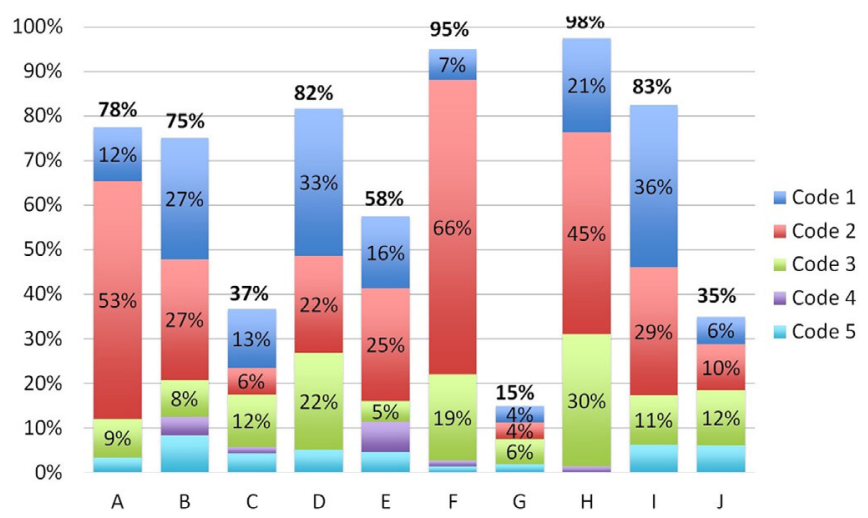

FIG. 4. The composition of social positions for each group in "roller coaster" activity, episode 2 . Columns represent percentage of $1,2,3,4$, and 5 codes as a fraction of total number of codes, scaled by the amount of coded time. 


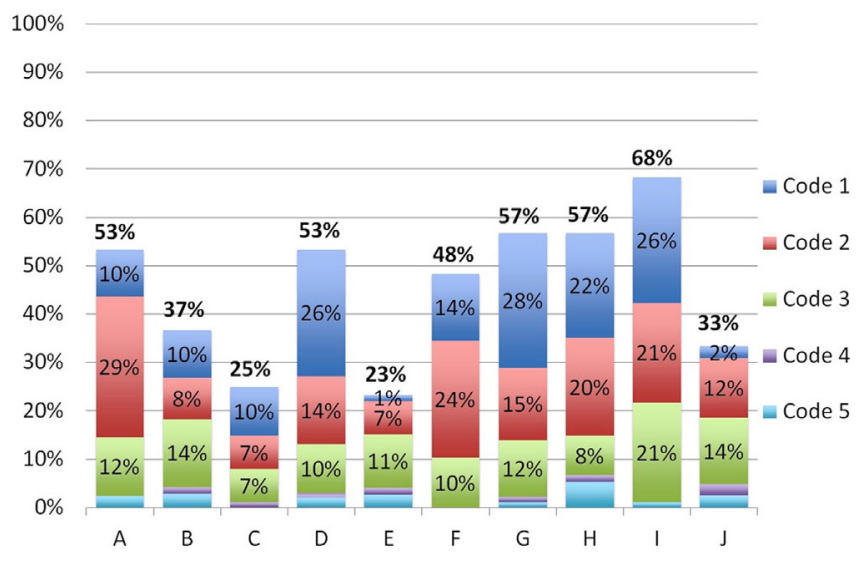

FIG. 5. The composition of social positions for each group in "energy bar-chart" activity, episode 3. Columns represent percentage of $1,2,3,4$, and 5 codes as a fraction of total number of codes, scaled by the amount of coded time.

Table III shows the average time that groups spent engaged in on-topic conversation, averaged across the three coded episodes.

Next, we coded the effectiveness of each group for each of the three activities they engaged in. The results of this coding are shown in Table IV, ranked from overall most to least effective.

There are three key patterns we can observe from these data. There are some groups that do not talk much to each other about the physics topic as compared to all other groups. These are groups C, E, G, and J, as indicated by their total amount of interaction in the figures and table. Across the three coded episodes their average interaction times were $29 \%, 37 \%, 43 \%$, and $39 \%$, respectively (see Table III). The next lowest group (group B) interacted an average of $57 \%$ of the time. It turned out that these four groups were also the 4 least effective groups in the class (see Table IV). Perhaps unsurprisingly, group members need to talk to each other about the topic in order to engage in sense making and learning as a group. Focusing only on

TABLE III. Total time spent talking about the topic averaged across three episodes. Note: because some segments are longer than others, they carry more weight in the average.

\begin{tabular}{lcc}
\hline \hline Group & Total interaction $\%$ & Rank \\
\hline F & $74 \%$ & 1 \\
I & $73 \%$ & 2 \\
H & $72 \%$ & 3 \\
A & $69 \%$ & 4 \\
D & $67 \%$ & 5 \\
B & $57 \%$ & 6 \\
G & $43 \%$ & 7 \\
J & $39 \%$ & 8 \\
E & $37 \%$ & 9 \\
C & $29 \%$ & 10 \\
\hline \hline
\end{tabular}

TABLE IV. Groups'effectiveness score (Effect) for each episode and ranked by total effectiveness score from highest to lowest.

\begin{tabular}{lccccc}
\hline \hline Rank & Group & Effect (E1) & Effect (E2) & Effect (E3) & Effect total \\
\hline 1 & A & 10 & 14 & 11 & 35 \\
2 & F & 10 & 14 & 9 & 33 \\
3 & H & 7 & 9 & 6 & 22 \\
4 & I & 6 & 6 & 8 & 20 \\
5 & D & 5 & 6 & 7 & 18 \\
6 & B & 5 & 5 & 6 & 16 \\
7 & C & 3 & 4 & 6 & 13 \\
8 & G & 5 & 0 & 5 & 10 \\
9 & J & 5 & 1 & 3 & 9 \\
10 & E & 4 & 4 & 0 & 8 \\
\hline \hline
\end{tabular}

the remaining 6 groups, who spent significantly more of their time engaged in on-topic conversation, these groups display very distinct distributions of positional moves. One pattern in particular stands out: Members of groups $\mathrm{A}$ and F consistently adopted the "intermediate expert" position (code 2) more frequently than the expert position (code 1) across all 3 episodes. They stand apart from the other 4 groups except for one occasion in episode 2 when group $\mathrm{H}$ matched this code 2 versus code 1 distribution. While on-topic conversation seems generally predictive of group effectiveness (the four least effective groups spend the least amount of time engaged in on-topic conversation), there is no correlation between the amount of time spent on topic and group effectiveness among the top 6 groups. This fact, combined with the notable pattern of interaction displayed by groups A and F, motivated the next part of our analysis.

\section{The relationship between group equality and group effectiveness}

According to the ideas presented so far, code 2 and code 3 represent conversations that promote equality among group members, while code 1 and code 4 conversations do the opposite, they promote inequality among group members. Therefore we defined a "group equality" score by adding the number of 2 and 3 codes for each group and subtracting from that, the combined total of 1 and 4 codes. The larger the equality score, the more equal that group is in their discussions. Group equality scores are shown in Table V, ranked from most equal to least (highest to lowest).

Table $\mathrm{V}$ shows that groups $\mathrm{A}$ and $\mathrm{F}$ exhibit a distinctive pattern across the 3 episodes. In these two groups, the percentage of code $2+$ code 3 is consistently larger, while their percentage of code $1+$ code 4 is consistently smaller than groups B, D, H, and I, who all share a similar amount of total interaction time. Notice that for group $\mathrm{J}$, their equality score is quite high, while their total amount of interactions remain low. This was a result of a regularly occurring group dynamic that we will examine in greater 
TABLE V. Group equality score (Eq.): Difference $(2+3)$ codes $-(1+4)$ codes ranked from overall highest to lowest.

\begin{tabular}{lccccc}
\hline \hline Rank & Group & Eq. (E1) & Eq. (E2) & Eq. (E3) & Eq. avg. \\
\hline 1 & F & 24 & 56 & 18 & 32.7 \\
2 & A & 27 & 29 & 26 & 27.3 \\
3 & H & 0 & 37 & 4 & 13.7 \\
4 & J & 2 & 8 & 17 & 9.0 \\
5 & B & 5 & 2 & 8 & 5.0 \\
6 & E & -2 & 3 & 11 & 4.0 \\
7 & C & -1 & 2 & 2 & 1.0 \\
8 & D & -10 & 10 & -3 & -1.0 \\
9 & G & -7 & 3 & -2 & -2.0 \\
10 & I & -24 & 2 & 14 & -2.7 \\
\hline \hline
\end{tabular}

detail in Sec. IV B below. The short summary is that a member from group $\mathrm{J}$ made bids to start a conversation with other group members by making statements with hedging words and asking meaningful questions. However, his positional moves were not taken up by other group members; the initiating group member was either rebuffed with emphatic statements (code 1) or was simply ignored by other group members. As a result, the conversation petered out [31].

For example, in episode 3

Donald: What do we do with the bar chart?,

[Long silence, the other group members do not respond.]

Donald: So it started with kinetic energy [tailing off], and then no kinetic energy,

[Other group members remain silent]

The interaction ended there. Notice that Donald made two bids to start a discussion: first with an intermediate novice position (code 3), and then with an intermediate expert position (code 2). Both attempts amount to bids to engage other group members. However, neither of these 2 positional moves were recognized by his colleagues, and collaboration did not happen. Our data suggests that equal positioning (measured by the equality scores) is a necessary but not a sufficient condition for the group to be effective.

While groups like group $\mathbf{J}$ are interesting in their own right, they are not the focus of our research questions in this paper. As mentioned in the introduction, we are trying to understand why some groups outperform others in their learning effectiveness, irrespective of how much they interact with each other. Groups A, B, D, F, H, and I are thus the groups we want to focus on.

In Table VI we performed a set of rank-order correlation tests comparing the effectiveness of the top 6 groups to their group equality score across the three episodes.

It is necessary to use a nonparametric permutation test to estimate $p$ values because of our small sample size, which violates most of the inherent assumptions of the standard parametric tests, namely, homoscedasticity, normal distribution, etc. Following the recommendation of Lakens et al. [39], we are deliberately avoiding the term "statistical significance" in our analysis. Rather, following Lakens's recommendation [39], we examine what $\alpha$ level is appropriate for us to observe a large effect in the potential relation between group effectiveness and equality score. According to Cohen [40], an effect size $r^{2}=0.25(r=0.5)$ is considered to be the minimum boundary for a "large effect." The probability $p$ of this happening by random chance in a sample of $n=6$ is 0.3 . Thus we can consider any $p$ value lower than $0.3(r>0.5)$ to be indicative of a likely relation between group effectiveness and equality score. Each of the observed correlations between group effectiveness and equality score in Table VI are larger than 0.5 and all probabilities are less than 0.3 . Additionally, the probability that this association between group effectiveness and group equality occurred by random chance across the three episodes is $0.18 \times 0.06 \times 0.07=0.0008$. The null hypothesis that there is no association between group effectiveness and group equality can be rejected.

\section{B. Qualitative analysis}

The coding scheme above only captures limited aspects of how the group members are interacting with each other.

TABLE VI. Effectiveness versus equality score for the top 6 most talkative groups for all three episodes. Probability that each of these correlations happened by random chance $(p)$ was calculated using a nondirectional permutation test to create a sampling distribution of $r$ 's.

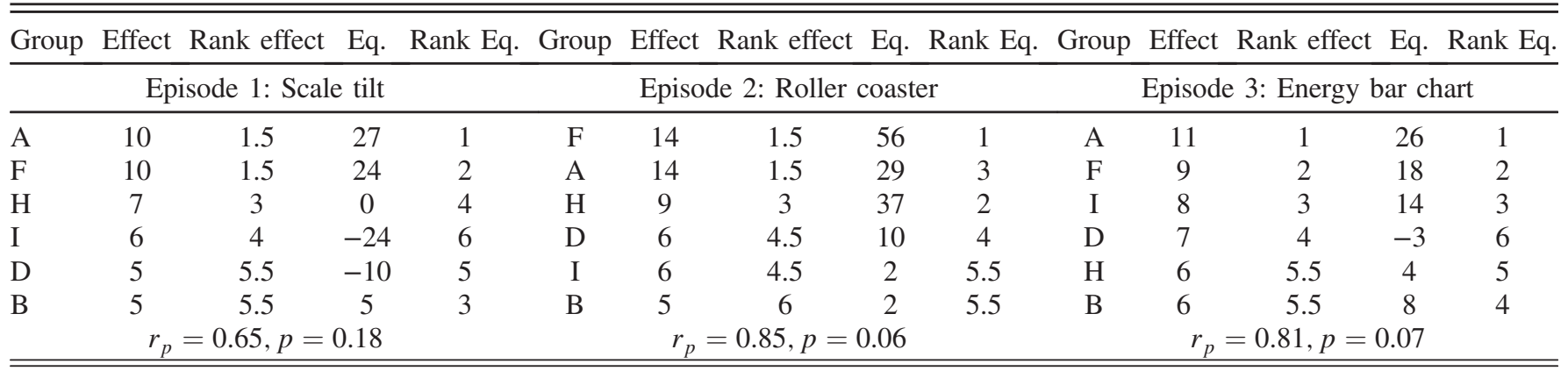


In this section we present a fuller or richer picture of the moment-by-moment dynamics that show what a more equal or a less equal conversation between group members looks like. In the following sections we will present three examples from, and draw contrasts between, groups A, D, and I. We focus on these three groups because they are comparable in terms of the amount of time they spend in conversation $(69 \%, 67 \%$, and $73 \%$, respectively) and yet their outcomes in terms of group effectiveness (average $11.7,6.0,6.7)$ are strikingly different. We will use these three examples to highlight a number of common patterns of behavior that we observed repeatedly throughout the episodes we coded.

\section{When bids to open the conversation fail}

The pattern of conversation we examine in this section was observed across multiple groups. Often a group member would try to open the conversation with another group member, either by asking questions or offering hedged statements ending in phrases like "right?" or "what do you think?" Instead of engaging in the conversation the second group member shut down the conversation with both (a) emphatic (code 1) statements that often came across as aggressive or condescending, and (b) by ignoring the group member who was trying to initiate the conversation. The following example from group $\mathrm{D}$ is a model example of this pattern of interaction with one group member employing both techniques to shut down the conversation. In the following excerpt from October 15 (episode 2) Group D are trying to draw a force diagram for a moving roller coaster car at the bottom of a circular loop.

[Ronald is talking to George. Robert is involved in a separate conversation with group C.]

Ronald: If the Earth was stronger it would be falling. George: Technically it wouldn't be falling because the... the force of... the rails pulling it up.

Ronald: What would the force diagram be for $(b)$ ?

[He raises his voice above the noise at the table and directs his gaze towards Robert. Robert ignores him and continues writing on the whiteboard-his conversation with group $C$ has ended by this point.]

[Ronald raises his voice louder-there is no mistaking he's trying to make sure Robert hears him above another conversation happening between the members of group $C$ next to them.]

Ronald: Like for (c) it's going down so the force of the Earth is longer or it would be falling.

Robert: Yeah, it's going to be balanced there too. So if you are making a top view, then there's acceleration towards the radial direction. If it's the frontal view, then like, the upward forces are balanced because it's not really moving up or down. It's just moving in a circle. Ronald: But in terms of the force diagram...
Robert: Yeah, I know. There's acceleration in the radial direction, that's it.

Ronald: But what does that tell you about force?

Robert: Huh?

Ronald: What does that tell you about force? You have acceleration in the radial direction, but what about the force, up and down?

Robert: If you have force in the radial direction, I mean acceleration in the radial direction, you have force in the radial direction.

Ronald: What would the force diagram be... [inaudible as Robert talks over him.]

Robert: Huh?

Ronald: What would the force diagram be?

Robert: Pointing towards the center.

Ronald: Yeah?

Robert: Yeah, that's it!

Ronald: From a top view...

Robert: From a top view, yeah.

George: But [inaudible] the force going upwards though, also.

[Robert ignores him and continues drawing on the whiteboard.]

This short excerpt epitomizes the failure of what could have turned into a productive conversation and shows how expert positioning can lead to a dynamic of inequality in the group. The group has already established that the upward force exerted by the track on the car balances the downward force exerted by Earth on the car in the previous case of moving along a horizontal track at constant velocity. Now, Ronald is trying to understand how to draw a force diagram for the next case and seems to recognize that it shouldn't be the same as before, but appears unsure how to continue. Instead of using Ronald's questions as a chance to open up a dialogue, Robert shuts down the conversation. In the excerpt above Robert mostly maintains an expert position (code 1). Robert comes across as dismissive of Ronald's repeated questioning when he cuts across him saying "huh?" and instead of just providing affirmation he says "Yeah, that's it!" in an emphatic downward inflection.

While one group member can make bids to open the collaborative space through hedged statements (code 2) and focused questions (code 3 ), the other group members must necessarily listen to and respect the statement or question and take it up, integrating it into the conversation. The need for mutual respect is a key factor that we found in our deeper qualitative analysis.

\section{In effective groups, everyone's contribution matters}

Contrast the conversation above with the next excerpt from group A. Superficially the two groups are similar in the sense that (a) they spend roughly the same amount of time talking, and (b) similar to Robert in group D, one person (José) is controlling the whiteboard and markers. 
In this excerpt from episode 1, group $\mathrm{A}$ is working on trying to draw force diagrams for the cases of a horizontal scale and a tilted scale. (Episode 1, October 3.)

José: So, force of Earth on weight,

Nancy: And...

Nancy and José in unison: force of scale...

Jessica: They're equal to each other [inaudible]

José: Is there...? would we include...? No, there's no...

Jessica: no, [inaudible] it's not moving.

Nancy: And then you put the little...

José Oh, but now there is...

Nancy: Yes

José: In this one.

Jessica: [inaudible] is holding it up.

José: Right, so then in this case...

Nancy: You still have earth acting upon it not as strong.

José: And it's the same [draws]... as this one, right?

Nancy: Yes. And then...

José: Now.

Jessica: So for the scale it's less. [upward inflection, coded as a hedge (code 2).]

Nancy: It's, it's more this way, right?

José: So...

Nancy: It's going like that.

In this short excerpt one can observe a number of behaviors that we found to be typical of the two most effective groups, A and F. Although José is doing the writing and, from our more general observations, is seen as the group leader, he is not controlling the conversation. All three members display a remarkable pattern of turn-taking and overlapping complementary conversation, that shows that the three group members are positioned as equals. The transcript shows how participants overlap their conversation in a complementary way by completing each other's ideas rather than cutting each other off, sometimes even talking in unison. Everyone gets to contribute something to the conversation. Every group member says something valuable in this short 52-sec excerpt. More importantly each idea is taken up by the group. For example when Jessica says "... is holding it up." José immediately responds with "right."

During the $52 \mathrm{sec}$, José, Nancy, and Jessica all made a clearly hedged statement (coded 2) either by inserting a "right?" and the end of their statement (José and Nancy), or in Jessica's case by inflecting her statement upwards, making it sound more questionlike. These hedges open the space up for all group members to participate in an equitable way.

Roughly 6 min later group A reached an impasse because they incorrectly drew the force exerted by the scale plate on the object pointing vertically upwards even though the scale was tilted 10 degrees. This was one of the key points we identified in our group effectiveness coding that needed to be struggled with and resolved in order to successfully complete the activity.

José: We have to balance it out because it's not moving. The net force needs to be zero on the $y$ and the $x$.

[They have chosen to orient their coordinate system aligned with vertical and horizontal rather than aligned with the tilted scale]

Jessica: What if we break this one [leans over and points] if we break this up into an $x$ and $a y$. The $y$ component and this [points to the frictional force], the scale on the weight, would be equal to the force of the Earth on the weight and now we just need to figure out $x$.

José: So would those [inaudible] I mean...

Jessica: Perpendicular?

[José leans over, asks to borrow the scale from group $B$. They stare at the scale as he tilts it. Nancy measures the angle with a protractor, finds it to be 10 degrees and says "good job" to José and laughs.]

José: [looking at the weight on the scale] So, what's keeping it from moving? [rhetorical] There's the static friction that's holding it. It's making it go that way. It's just like, the direction of the surface.

[Long 20-sec silence, all three group members stare at the scale. José asks group B sitting opposite to explain their force diagram.]

This excerpt highlights a common pattern of behaviors of both groups A and F. They were unable to reach a resolution on their own at this point, but because they were listening to and respecting each other's ideas, they recognize they have something that is inconsistent (in this case an unbalanced force) that needs resolving. Instead of moving on they are able to struggle with the inconsistency and try to resolve it, first by employing standard representational resources of physics and, second, by using hedged statements and asking probing questions that engaged all three group members in the conversation.

\section{When two group members butt heads}

The following excerpt from group I illustrates what frequently happened when two group members both positioned themselves as experts (code 1) but on opposite sides of an issue. In the following excerpt from episode 1 the group has just finished watching the reading on the tilted scale decrease.

James: Why? [referring to the decreased scale reading.]

Lisa: Draw a force diagram for each situation.

[Gary starts drawing on the board. James immediately interrupts him]

James: No, no, draw a tilted, a tilted... Instead of drawing like that, draw it like this 
[James: draws a cross with his finger hovering over the whiteboard, the cross is oriented diagonally like $\times$ rather than + .]

Gary: Huh? What is it? It's supposed to be like this.

Force of the Earth is still going down!

James: Ya

Gary: What are you talking about?

Gary: $x$ and $y$ would still be $x$ and $y$ [He draws a cross with his finger hovering over the whiteboard, the cross is oriented.+$]$

James: [continues drawing, speaking quietly] So, so so, it will be much better for us.

Gary: That makes no sense. $x$ and $y$ is still, even though it... even though it's tilted, $x$ is still $x, y$ is still $y$ [gestures down then sideways with his index finger]

Gary: Oh my god, here, [places a marker down hard on the whiteboard in front of James] do yours.

James's idea is productive. Tilting the coordinate system is a significant step in this activity. Consistent with the findings of Fragale [33] (that unhedged statements are accorded lower status in highly task-involved tasks) Gary did not give James's unhedged idea much consideration. A mutual disrespect between Gary and James quickly devolved to the point they continued working separately on the same force diagram instead of engaging in the necessary productive struggle to solve the critical aspects of the activity.

\section{DISCUSSION AND CONCLUSION}

We have found a correlation between group effectiveness and group equality as indicated by the amount of time group members spend positioning themselves in the positions of intermediate novice and intermediate expert. From our quantitative and qualitative analysis, it appears that the most effective groups display a cluster of behaviors [41] that complement each other in a myriad of ways that are beyond the scope of this paper to elaborate. Not only do they have more equal conversations and are better able to sustain their attention during periods of adversity and frustration, they also, according to our observations, sit closer to each other and often are the first groups to start a new activity. In addition, group dynamics vary from day to day. Some groups are consistently more effective than others. But we observed days when group $\mathrm{H}$ (for example) worked quite effectively together, and when they did their equality score increased.

The qualitative analysis shows that the underlying factors of respect and psychological safety are also key for a group to be successful. We suggest that the theme of respect that emerged from our qualitative analysis is connected to positioning because it is difficult or impossible to convey mutual respect if group members are constantly positioning themselves as experts. As we have shown, one student can make bids to engage by hedging their language or asking questions, but can be rebuffed, or completely ignored by another group member. In the examples, the ensuing silence quickly leads to frustration and failure (the task was not completed). In other words, hedged statements only work when the ideas contained therein are acknowledged and taken up by other group members. While adding uncertainty to a statement may increase the probability of that idea being heard, it does not guarantee it. We have observed that it takes only one group member to "sabotage" a productive conversation.

What possible mechanism could there be behind why hedged statements and meaningful questions are such clear indicators of an effective group? We hypothesize that, for a participant to position themselves as an intermediate expert or intermediate novice, it takes a conscious effort and intentionality to learn and explore in a state of discomfort and uncertainty. In contrast, assuming the position of expert when you are not $100 \%$ certain entails some degree of bluster, pretending that you know what you are talking about more than you really do. Alternatively, making an emphatic statement may simply be a quick way to get to a desired conversational end point, while adding a hedge when you feel $100 \%$ confident in your response, requires a certain level of conscious social sensitivity and willingness to prolong the conversation. We have noticed this in transforming our own practice in communicating with colleagues and students: We have discovered that adding a right? at the end of a statement is highly effective in opening the space to the contributions of other participants in the conversation. Yet, it takes a level of conscious mental effort to remember to soften one's tone. Taking on the novice position may involve either (a) Asking to be fed information without too much intellectual input ("What is the answer to this problem?") or (b) may arise because of task avoidance ("I have no idea what is going on here"). Both expert and novice positions can both clearly have a detrimental effect on group learning effectiveness that requires group members to explore difficult questions and be comfortable with uncertainty.

\section{A. Limitations of the study}

While we have found that group effectiveness is correlated with group equality score (based on the positioning of the group members), we cannot conclude there is a causal link between the two. Additionally our sample size is small and our study is limited to a unique physics class that is focused on students figuring physics out for themselves and building a consensus through discussion. We have, however, found some generalizability of our results. In another study that applied the coding scheme developed in this paper to a whole-class discussion of about 20 physics students, it was found that successful consensus building was strongly connected with the amount and frequency of hedged statements during a discussion about a contentious physics idea [42]. 


\section{B. Implications for instruction}

As mentioned previously, we do not suggest a causal link between the social positioning of group members and the effectiveness of the group. Therefore, telling group members to "soften your tone" when talking to each other is probably not going to be an effective way to improve group dynamics. Rather, we suspect that mutual respect and a shared orientation towards the task among group members form the basis for a cluster of behaviors that manifest themselves in these particular idiosyncratic patterns of discourse. We believe our research supports and is aligned with the work of Tobin and colleagues who talk about training students in the skill of "cogenerative dialoguing" so that they can safely identify issues and transform their group practice $[43,44]$. It is striking that in a classroom that emphasized collaborative learning, only two groups out of ten showed evidence they were able to collaborate effectively on a regular basis. It appears that effective collaboration is rare, rather than the norm. We suggest that groups of students may benefit from explicit training in how to work together in a more effective way, learning to understand the benefit of listening to the ideas and questions of all group members and valuing the diverse contributions that different group members may bring to the table.

\section{ACKNOWLEDGMENTS}

We thank Eugenia Etkina for reading and editing our manuscript and José Robles for drawing our attention to the importance of mutual respect among group members. We thank three anonymous reviewers for their insightful and constructive comments which greatly improved our paper.
[1] E. Etkina and A. Van Heuvelen, Investigative science learning environment-A science process approach to learning physics, in Research-Based Reform of University Physics, Vol. 1, edited by E. F. Redish and P. J. Cooney (2007), https://www.per-central.org/items/detail.cfm?ID=4988.

[2] J. M. Wilson, The CUPLE physics studio, Phys. Teach. 32, 518 (1994).

[3] E. Etkina, Millikan Award lecture: Students of physicsListeners, observers, or collaborative participants in physics scientific practices?, Am. J. Phys. 83, 669 (2015).

[4] E. Etkina, A. Karelina, M. Ruibal-Villasenor, D. Rosengrant, R. Jordan, and C. E. Hmelo-Silver, Design and reflection help students develop scientific abilities: Learning in introductory physics laboratories, J. Learn. Sci. 19, 54 (2010).

[5] D. T. Brookes, E. Etkina, and G. Planinsic, Implementing an epistemologically authentic approach to studentcentered inquiry learning, Phys. Rev. Phys. Educ. Res. 16, 020148 (2020).

[6] K. Bielaczyc and A. Collins, Learning communities in classrooms: A reconceptualization of educational practice, in Instructional Design Theories and Models, Vol. II, edited by C. M. Reigeluth (Lawrence Erlbaum Associates, Mahwah, NJ, 1999), Chap. 12, pp. 269-292.

[7] D. M. Desbien, Modeling discourse management compared to other classroom management styles in university physics, Ph.D. Thesis, Arizona State University, 2002.

[8] B. E. Hinrichs, Sharp initial disagreements then consensus in a student led whole-class discussion, in Proceedings of the 2013 Physics Education Research Conference, edited by P. V. Engelhardt, A. D. Churukian, and D. L. Jones (AIP, New York, 2014), pp. 181-184.

[9] B. G. Glaser and A. L. Strauss, The Discovery of Grounded Theory (Aldine Publishing Company, Chicago, 1967).

[10] B. Nainabasti, D. T. Brookes, Y. Yang, and Y. Lin, Connection between participation in an Interactive Learning Environment and learning through teamwork, in Proceedings of the 2015 Physics Education Research Conference, edited by A. D. Churukian, D. L. Jones, and L. Ding (AIP, New York, 2015), pp. 231-234.

[11] B. Nainabasti, D. T. Brookes, and Y. Yang, Students' participation and its relationship to success in an Interactive Learning Environment, in Proceedings of the 2014 Physics Education Research Conference, edited by P. V. Engelhardt, A. D. Churukian, and D. L. Jones (AIP, New York, 2015), pp. 195-198.

[12] A. Sfard, When the rules of discourse change, but nobody tells you: Making sense of mathematics learning from a commognitive standpoint, J. Learn. Sci. 16, 565 (2007).

[13] M. Scardamalia and C. Bereiter, Computer support for knowledge-building communities, J. Learn. Sci. 3, 265 (1994).

[14] J. Lave and E. Wenger, Situated Learning: Legitimate Peripheral Participation (Cambridge University Press, Cambridge, England, 1991).

[15] B. Rogoff, E. Matusov, and C. White, Models of teaching and learning: Participation in a community of learners, in Handbook of Education and Human Development, edited by D. R. Olson and N. Torrance (Blackwell, Oxford, UK, 1996), Chap. 18, pp. 388-414.

[16] A. Van Heuvelen, Learning to think like a physicist: A review of research-based instructional strategies, Am. J. Phys. 59, 891 (1991).

[17] J. Airey and C. Linder, Social semiotics in university physics education, in Multiple Representations in Physics Education, edited by D. F. Treagust, R. Duit, and H. E. Fisher (Springer Nature, Cham, Switzerland, 2017), Chap. 5, pp. 95-122.

[18] E. Etkina, D. T. Brookes, and G. Planinsic, Investigative Science Learning Environment when Learning Physics Mirrors Doing Physics (Morgan \& Claypool, San Rafael, CA, 2019). 
[19] C. A. Chinn and B. A. Malhotra, Epistemologically authentic inquiry in schools: A theoretical framework for evaluating inquiry tasks, Sci. Educ. 86, 175 (2002).

[20] R. Wageman, Interdependence and group effectiveness, Admin. Sci. Quart. 40, 145 (1995).

[21] P. Van den Bossche, W. H. Gijselaers, M. Segers, and P. A. Kirschner, Social and cognitive factors driving teamwork in collaborative learning environments: Team learning beliefs and behaviors, Small Gr. Res. 37, 490 (2006).

[22] J. Roschelle, Learning by collaborating: Convergent conceptual change, J. Learn. Sci. 2, 235 (1992).

[23] B. Barron, When smart groups fail, J. Learn. Sci. 12, 307 (2003).

[24] M. Menekse and M. T. H. Chi, The role of collaborative interactions versus individual construction on students' learning of engineering concepts, Eur. J. Eng. Educ. 44, 702 (2019).

[25] D. Mesch, D. W. Johnson, and R. Johnson, Impact of positive interdependence and academic group contingencies on achievement, J. Soc. Psychol. 128, 345 (1988).

[26] S. T. Bossert, Cooperative activities in the classroom, Rev. Res. Educ. 15, 225 (1988).

[27] A. Williams Woolley, C. F. Chabris, A. Pentland, N. Hashmi, and T. W. Malone, Evidence for a collective intelligence factor in the performance of human groups, Science 330, 686 (2010).

[28] A. Edmondson, Psychological safety and learning behavior in work teams, Admin. Sci. Quart. 44, 350 (1999).

[29] J. Rozovsky, The five keys to a successful Google team (2015), https://rework.withgoogle.com/blog/five-keys-toa-successful-google-team/.

[30] I. Esmonde, Ideas and identities: Supporting equity in cooperative mathematics learning, Rev. Educ. Res. 79, 1008 (2009).

[31] N. Bonderup Dohn, Explaining the significance of participationist approaches for understanding students' knowledge acquisition, Educ. Psychol. 51, 188 (2016).

[32] L. D. Conlin and R. E. Scherr, Making space to sensemake: Epistemic distancing in small group physics discussions, Cognit. Instr. 36, 396 (2018).
[33] A. R. Fragale, The power of powerless speech: The effects of speech style and task interdependence on status conferral, Organ. Behav. Hum. Dec. 101, 243 (2006).

[34] E. Karkkainen, Stance taking in conversation: From subjectivity to intersubjectivity, Text Talk 26, 699 (2006).

[35] M. A. K. Halliday, An Introduction to Functional Grammar (Edward Arnold, London, 1985).

[36] E. Etkina, D. Brookes, G. Planinsic, and A. Van Heuvelen, Active Learning Guide for College Physics: Explore and Apply, 2nd ed. (Pearson, San Francisco, CA, 2019).

[37] L.S. Vygotsky, Mind in Society: The Development of Higher Psychological Processes (Harvard University Press, Cambridge, MA, 1978).

[38] R. J. Beichner, J. M. Saul, D. S. Abbott, J. J. Morse, D. L. Deardorff, R. J. Allain, S. W. Bonham, M. H. Dancy, and J. S. Risley, Student-Centered Activities for Large Enrollment Undergraduate Programs (SCALE-UP) project, in Research-Based Reform of University Physics, Vol. 1, edited by E. F. Redish and P. J. Cooney (2007), https:// www.per-central.org/items/detail.cfm?ID=4517.

[39] D. Lakens et al., Justify your alpha, Nature Human Behav. 2, 168 (2018).

[40] J. Cohen, A power primer, Psychol. Bull. 112, 155 (1992).

[41] R. E. Scherr and D. Hammer, Student behavior and epistemological framing: Examples from collaborative active-learning activities in physics, Cognit. Instr. 27, 147 (2009).

[42] D. T. Brookes, B. E. Hinrichs, and J. L. Nass, Social positioning correlates with consensus building in two contentious large-group meetings, in Proceedings of the 2019 Physics Education Research Conference, Provo, UT, edited by Y. Cao, S. Wolf, and M. B. Bennett (AIP, New York, 2020)

[43] K. Tobin and W.-M. Roth, Implementing coteaching and cogenerative dialoguing in urban science education, School Sci. Math. 105, 313 (2005).

[44] K. Tobin, Fostering science learning in diverse urban settings, in Proceedings of the 2008 Physics Education Research Conference, Vol. 1064, edited by C. Henderson, M. Sabella, and L. Hsu (AIP, New York, 2008), pp. 50-52. 